\title{
Melanotic Psammomatous Malignant Peripheral Nerve Sheath Tumor
}

National Cancer Institute

\section{Source}

National Cancer Institute. Melanotic Psammomatous Malignant Peripheral Nerve Sheath

Tumor. NCl Thesaurus. Code C6910.

A malignant peripheral nerve sheath tumor characterized by the presence of malignant cells that contain melanin and formation of psammoma bodies. 